\title{
Recurrent Angiosarcoma
}

National Cancer Institute

\section{Source}

National Cancer Institute. Recurrent Angiosarcoma. NCI Thesaurus. Code C5384.

The reemergence of angiosarcoma after a period of remission. 